\title{
ПРЯМОЕ СПЕКТРАЛЬНОЕ ОПРЕДЕЛЕНИЕ МИКРОЭЛЕМЕНТОВ В ДИКТИОНЕМОВОМ СЛАНЦЕ МЕТОДОМ БУМАЖНОГО ШТАБИКА
}

Количественные методы спектрального анализа для одновременного определения большой группы микроэлементов в диктионемовом сланце до настоящего времени не применялись. Классический метод анализа, заключающийся в сжигании пробы в кратере угольного электрода, из-за резко выраженного фракционированного испарения элементов не позволяет выбирать оптимального режима дуги, наиболее подходящих эталонов и внутренних стандартов одновременно для многих элементов. Кроме того, в кратере нельзя сжигать пробы диктионемового сланца без их предварительного озоления из-за выброса вещества из кратера. Однако к экспрессным методам озоления, больше всего подходящим для подготовки проб к спектральному анализу, следует относиться с осторожностью, так как они нередко являются причиной потерь микроэлементов. При анализе проб в виде золы необходимо дополнительно определять и зольность для пересчета данных на исходную пробу.

При методах непрерывного введения порошковых проб в источник возбуждения (просыпка, вдувание и др.) фракционированное испарение элементов проявляется значительно слабее, что создает более благоприятные условия для определения большой труппы элементов. Анализ диктионемового сланца по методу просыпки (Русанов, Алексеева, Хитров, 1960) или вдувания (Русанов, Воробьев, 1964) усложняется сгоранием органического вещества в источнике возбуждения, что приводит к сильному уЕеличению фона в спектре. Общим недостатком этих двух методов является также низкая степень испарения пробы и большая зависимость результатов анализа от измельченности, сыпучести и гигроскопичности пробы. При методе поршневого электрода (Финкин, Дубосарская, 1966) проба испаряется наиболее полно, но для непосредственного анализа проб, содержащих органику, этот метод непригоден (из-за выброса вещества из электрода).

Методические работы по усовершенствованию методов количественного спектрального анализа диктионемового сланца в литературе отсутствуют.

В настоящей статье дается описание разработанной в Институте геологии АН ЭССР методики спектрального определения группы микроэлементов в диктионемовом сланце без предварительного озоления пробы. Для этой цели в принципе больше всего подходит метод бумажного штабика, разработанный для определения микроэлементов в сульфидном концентрате при химико-спектральном анализе кукерсита (Иоханнес, 1966). Применение этого метода к диктионемовому сланцу требует изменения техники приготовления штабиков и химической обработки пробы для перевода микроэлементов в легколетучие соединения, так как метод бумажного штабика в общем применим для сжигания сравнительно легкоиспаряемых веществ. 
Поскольку относительно высокое содержание в диктионемовом сланце ряда микроэлементов ( $\mathrm{Pb}, \mathrm{Ni}, \mathrm{Mo}, \mathrm{V}, \mathrm{Cr}, \mathrm{Ba}, \mathrm{Mn}, \mathrm{Cu}$ и др.) позволяет определить их в исходных пробах без заметного повышения чувствительности анализа, то основное внимание уделялось усовершенствованию техники анализа и увеличению воспроизводимости и точности определения элементов.

Сущность метода бумажного штабика заключается в следующем. Тонкоизмельченный порошок насыпается на полоску фильтровальной бумаги, которая затем смачивается раствором спектроскопического буфера (лимоннокислый литий) и свертывается во влажном состоянии в тонкий штабик. Последний вводится постепенно и равномерно в направлении снизу вверх в дугу переменного тока, горящую между горизонтальными угольными электродами. Регулирование скорости подачи и точное введение штабика в центр дуги, в зону высоких температур, позволяют достигать более полного испарения вещества. Обугливание органического вещества пробы и бумажной массы происходит постепенно в верхней части штабика при относительно низкой темперагуре вне дуги, чем этот метод отличается от методов просыпки, вдувания и поршневого электрода.

Благодаря непрерывному поступлению новых количеств пробы в дугу процесс испарения вещества и состав паров в дуге во времени не нзменяются. Исследование кинетики испарения элементов показало, что кривые испарения у всех элементов, включая элементы породообразующих компонентов ( $\mathrm{Si}, \mathrm{Al}, \mathrm{Mg}, \mathrm{Ca})$, по своей форме почти одинаковы и приближаются к прямым. Это свидетельствует об одновременном поступлении в дугу всех микро- и макрокомпонентов и об отсутствии заметного фракционированного испарения элементов.

Литий в качестве спектроскопического буфера также поступает в дугу с постоянной скоростью (благодаря равномерности пропитывания штабика раствором лимоннокислого лития), что позволяет эффективно стабилизировать горение дуги на протяжении всей экспозиции.

Приготовление штабиков. Из беззольной фильтровальной бумаги «красная (белая) лента» вырезается прямоугольная полоска длиной 11 и шириной 3,5 см, которая складывается по длине так, чтобы линия изгиба разделила бумагу на две части шириной $1-1,5$ и $2-2,5$ см. Бумага берется в левую руку более узкой частью к себе. В сгиб бумаги насыпается порошок пробы $(20$ мг) и распределяется стеклянной палочкой равномерно на протяжении 7 см, нричем правый конец остается свободным от пробы на 1 cм, а левый (ножка штабика) - на 3 c.. Целесообразно отмечать чернильными точками место расположения пробы на внешней стороне сгиба бумаги. Затем бумага пропитывается $20 \%$-ным раствором лимоннокислого лития до слегка влажного состояния с помощью пипетки капельницы с той стороны, где находится проба (стекание капель по бумаге не допускается). После этого бумага кладется на пластинку из органического стекла $(20 \times 35$ c. $)$ узкой полоской сгиба кверху и ножкой к себе. Сложенная таким образом бумага с пробой прижимается по всей длине к пластинке левой рукой с помощью стеклянной палочки. С помощью другой пластинки (13 $X$ Х 25 cм) бумага свертывается без сильного нажима вокруг стеклянной палочки так, чтобы сгиб бумаги оказался внутри. Затем стеклянная палочка вынимается и бумага свертывается в тонкий плотный штабик, который ставится в штатив (пластинка из толстого органического стекла с отверстиями для ножки штабика). 
При работе со штабиками особенно необходимо тщательно следить за чистотой рук и инструментов. Штабики можно брать рукой только за ножку. Необходимо позаботиться и о качестве фильтровальной бумаги, хотя при определении микроэлементов в диктионемовом сланце специальной очистки бумаги не требуется (см. Бабко, Марченко, 1957).

Правильность смачивания штабика раствором спектроскопического буфера устанавливается по стабильности горения дуги. Если дуга при сжигании штабика гудит тихо и равномерно, то это значит, что количество буфера взято правильно. Резкое потрескивание и нестабильное положение столба дуги указывают на недостаточное количество буфера. Очистка раствора лимоннокислого лития производится экстракцией дитизоном.

Навески проб диктионемового сланца взвешиваются на аналитических весах с точностью 0,2 ме. Затрата времени на точность взвешивания окупается улучшением вопроизводимости анализа. Навеска пробы должна быть не больше 20 мг, так как излишнее количество пробы приводит к усложнению процесса испарения.

Следует тщательно усреднять пробы. Твердые частицы пирита и кварца в мягкой массе органического и глинистого материала диктионемового сланца измельчаются с трудом и затрудняют получение гомогенного порошка. Измельчение целесообразно проводить в механической ступке до состояния пудры. Продолжительность измельчения зависит от качества ступки и определяется эмпирически по максимальной воспроизводимости параллельных анализов.

Обработка штабиков парами плавиковой кислоты. Эта операция необходима по двум причинам. Во-первых, перевод компонентов пробы во фториды, большинство которых относительно легко улетучивается, спссобствует более полному и интенсивному испарению пробы без образования больших жидких капель, которые испаряются медленно и чрезмерно удлиняют время экспозиции. Во-вторых, эта операция совершается с целью увеличения идентичности микро- и макрокомпонентов пробы с синтетическими эталонами.

Для достижения более эффективного и универсального действия применяется смесь плавиковой и азотной кислот в присутствии серной кислоты, повышающей парциальные давления паров двух первых. Обработка штабиков парами кислот производится в герметической камере из органического стекла. Камера состоит из бездонного ящика, плотно прижатого к пластинке-подставке. Нижние края ящика отшлифованы и смазаны вазелином. В камере помещается штатив со штабиками и платиновая чашка со смесью кислот. Кислоты приливаются в следующем порядке: серная кислота - до закрытия камеры, плавиковая и азотная - после закрытия, последовательно через отверстие в камере (закрывается пробкой) с помощью полиэтиленовой воронки с длинной трубкой. Соотношение серной, плавиковой и азотной кислот $1: 1: 0,5$. Для ста проб расходуется 50 мл смеси кислот.

Штабики во влажном состоянии помещаются в камеру сразу после nx приготовления. Длительность обработки при комнатной температуре - 12 . После этого штабики держат 30 мин в парах аммиака, чтобы они в дальнейшем не выделяли паров кислот. Желательно иметь для спектрографа дополнительную вентиляционную трубу с колпаком, под которым можно поместить штатив со штабиками. Хотя обработка штабиков парами кислот при комнатной температуре длится часами, зато исключаются потери микроэлементов из-за улетучивания фторидов 
и упрощаются устройство камеры и техники ее обслуживания.

Применение фторирующих спектроскопических буферов (фтористые аммоний, литий и натрий) не дало столь надежных результатов, как фторирование проб в камере. В последнем случае происходит как бы двукратное фторирование: первый раз в камере, второй раз в дуге парами фтористого лития (который образуется в камере при реакции лимоннокислого лития с плавиковой кислотой). Фтористый литий является одновременно и отличным стабилизатором горения дуги.

В результате фторирования проб диктионемового сланца значительно повышается интенсивность испарения пробы и усиливается почернение спектральных линий почти всех элементов (табл. 1).

Таблица 1

Влияние фторирования проб диктионемового сланца на величину почернений спектральных линий элементов

\begin{tabular}{|c|c|c|c|c|c|c|c|c|c|c|c|c|c|c|c|c|c|}
\hline \multirow{2}{*}{ Проба } & \multicolumn{17}{|c|}{ Почернение $(S)$} \\
\hline & $\mathrm{Be}$ & $\mathrm{Pb}$ & $M n$ & $\mathrm{Ga}$ & V & $\mathrm{Ni}$ & Mo & $\mathrm{Zr}$ & $\mathrm{Cu}$ & Co & $\mathrm{Cr}$ & $\mathrm{Ba}$ & $\mathrm{Mg}$ & $\mathrm{Fe}$ & Al & $\mathrm{Ca}$ & $\mathrm{Ti}$ \\
\hline
\end{tabular}

Не обработана

$\begin{array}{llllllllllllllllllll}\mathrm{HF} & - & 0,45 & 0,86 & 0,27 & 0,70 & 0,60 & 0,35 & 0,12 & 1,18 & 0,10 & 0,04 & 0,08 & 0,05 & 0,05 & 0,23 & 0,10 & 0,0\end{array}$

Сжигание штабика в дуге. Для этого применяются два штатива. Псдача горизонтально расположенных угольных электродов осуществляется штативом из комплекта принадлежностей к спектрографам типа AC. Дополнительный штатив для подачи штабика вмонтирован в стенку камеры сжигания; он позволяет передвигать штабик по трем направлениям для точной установки его в центре дуги. Можно пользоваться штативами любого типа, обеспечивающими продвижение трех электродов в указанных направлениях.

За правильным положением конца штабика в центре дуги по направлению оптической оси спектрографа следят по его изображению на экране второго конденсора. Для установки штабика в центре дуги по направлению, перпендикулярному оптической оси спектрографа, необходимо вмонтировать в камеру сжигания дополнительную линзу и плоское зеркало.

Получение воспроизводимых результатов анализа зависит в большой мере и от вентиляционной системы камеры сжигания, так как потоки воздуха могут изменять положение и форму столба дуги и понижать ее температуру. Вентиляционное устройство камеры сжигания в заводском оформлении (с боковым выходом) не обеспечивает стабильности горения дуги по причине потоков воздуха в центральной части камеры. Для устранения этого недостатка выход вентиляционной трубы был сделан вверху камеры и сама камера снабжена двойными стенками. При таком устройстве камеры можно применять усиленную тягу и создавать между двойными стенками надежную воздушную завесу. В центре камеры заметных потоков воздуха не наблюдается (проверка по стабильности пламени обыкновенной свечи).

Сжигание штабика проводится следующим образом. Угольные электроды и штабики устанавливают правильно по их теневому изображению на экране второго конденсора. После этого штабик опускается на $1-1,5$ cм и включается дуга между электродами при закрытой щели спектрографа. Затем штабик поднимается в дугу и сжигается при за- 
крытой щели в течение примерно 10 сек до тех пор, пока верхний конец штабика (около 1 см) не обуглится и начнет тлеть. В это время излучение от штабика дает усиленный фон, поэтому экспонировать его не рекомендуется. Воспроизводимость анализа от этого не уменьшается, так как верхний конец штабика не содержит пробы. Холостое горение штабика в течение некоторого времени полезно, ввиду того, что в это время устанавливается постоянный режим горения дуги и вещество пробы начинает поступать уже в совершенно стабильный источник возбуждения.

Полное сгорание штабика в присутствии фтористого лития происходит в течение 4 мин (галогениды удлиняют время сгорания). Длительное время экспозиции несколько уменьшает производительность анализа, но зато позволяет получать более воспроизводимые результаты. Случайные изменения в режиме горения дуги и в процессах возбуждения элементов усредняются в течение 4 мин в бо́льшей степени, чем за 15-20 сек при сжигании методом просыпки и вдувания.

Спектры снимаются на спектрографе ИСП-22 при следующих условиях: ширина щели спектрографа - 0,010 мм; перед щелью - трехступенчатый ослабитель с пропусканием 10, 50 и 100\%; высота и ширина диафрагмы второго конденсора соответственно 3,5 и 5 мм; сила тска дуги (от генератора ДГ-2) - $12 a$; фотопластинки - спектральные, тип 1, 1,4 ед.

Проявление фотопластинки. Наилучшие результаты достигаются при медленном проявлении до высокой контрастности. Однако все контрасгные проявители действуют слишком быстро, а медленноработающие мелкозернистые проявители не позволяют получить достаточно высокой контрастности. Прибавление повышенных количеств бромистого калия к контрастным проявителям не приводит к эффективному замедлению проявления. В настоящей работе применялся мелкозернистый проявитель «Финал» (Микулин, 1960), в составе которого бромистый калий заменен бензотриазолом; 0,5 г этого реактива на $1 \Omega$ проявителя существенно не уменьшает чувствительности фотопластинки, но резко замедляет процесс проявления и повышает контрастность. Время проявления спектрограмм при температуре $20^{\circ}$ без перемешивания проявительного раствора - 60 мин. Кюветку с пластинкой желательно поставить в темный ящик, так как красный цвет в течение такого длительного времени все же может подействовать на фотопластинку. От применения указанного проявителя равномерность проявления значительно увеличилась. Коэффициент контрастности - больше единицы.

Градуировочные графики. Наибольшую точность при определенин содержания элементов дает прямолинейный график с наклоном $\geqslant 1$. Прямолинейный график обычно строится в координатах $\lg I, \lg C$ с переходом от почернений к интенсивности с помощью характеристической кривой. Однако точное построение полной характеристической кривой - нелегкая задача, отнимающая много времени. Имеются данные, что в области спектра 2500-3100 А̊ для каждой пластинки необходимо построить не одну характеристическую кривую, а несколько, через каждые $70 \AA$ (Gerbatsch, Bächer, 1967). Поэтому градуировочный график строят либо в координатах $S, \lg C$ по большому количеству точек, либо прибегают к выпрямлению кривых с помощью разных функций преобразования (Прокофьев, 1951; Vioque, Albi, 1966; Zimmer, Török, Asztalos, 1966). Применение в нашем случае $W-, P$-, $l$ - и $\lambda$-преобразований не дало положительных результатов. По-видимому, общие приемы вы- 
прямления применимы не во всех случаях (различия в качестве фотоматериала, проявителя и т. д.).

Для нас оказалось целесообразным отказаться от применения какого-либо сложного преобразования, позволяющего выпрямлять график в широком интервале почернений. Вместо этого были построены три типа графиков в координатах: $S, \lg C ; \lg S, \lg C ; S, C$. Градуировочный график прямолинеен в координатах $S, \lg C$ в своей центральной части $(0,3-0,5 \leqslant S \leqslant 1,2-1,3)$, график $\lg S, \lg C-$ в центральной часги и в области недодержек, начиная с $S=0,10-0,15$, а график $S, C$ - в области недодержек до $S=0,50-0,60$.

Использование графиков в трех координатах менее удобно, но зато для их построения применяются непосредственно величины почернения, бєз пересчета на другие переменные с помощью эмпирических констант преобразования, определение которых всегда связано с ошибкой. Для уменьшения ошибок, обусловленных случайными изменениями свойств фотопластинок и других условий анализа во времени, на каждую пластинку с пробами или эталонами трижды снимается контрольная проба, а сдвиг прямой части градуировочных кривых определяется по положению контрольных точек.

Эталоны. Метод бумажного штабика позволяет приготовлять вместо «классических» порошковых эталонов так называемые капельные эталоны: микроэлементы вводятся в эталоны путем непосредственного нанесения эталонных растворов на высушенные штабики с основой. Таким образом исключаются ошибки, обусловленные неоднородностью порошксвых эталонов. В отличие от последних, капельные эталоны легко составляются в самых различных комбинациях, и при их использовании отпадает длительное и трудоемкое перемешивание эталонных порошков в ступке. В качестве основы капельных эталонов применялся чнстый горный хрусталь и диктионемовый сланец с наименьшим содержанием микроэлементов, которые предварительно определялись методом добавок. Сопоставление градуировочных кривых, построенных по эталонам с указанными основами, показало, что в пределах ошибки анализа кривые совпадают, несмотря на различие в составе основ эталонов. Можно применять капельные эталоны и без основы, тогда необходимо учитывать различие фона в спектре эталонов и проб (фон в спектре проб выше).

Таблица 2

Чувствительность и воспроизводимость прямого спектрального анализа диктионемового сланца

\begin{tabular}{l|c|c|c}
\hline Элемент & $\begin{array}{c}\text { Аналитическая } \\
\text { линия, }\end{array}$ & $\begin{array}{c}\text { Относительная } \\
\text { чувствитель- } \\
\text { ность, \% }\end{array}$ & $\begin{array}{c}\text { Коэффициент } \\
\text { вариаци, \% }\end{array}$ \\
\hline $\mathrm{Be}$ & 2348,6 & 0,0001 & 8,0 \\
$\mathrm{Mn}$ & 2801,1 & 0,0005 & 6,0 \\
$\mathrm{~Pb}$ & 2833,1 & 0,001 & 7,5 \\
$\mathrm{Ga}$ & 2943,6 & 0,0003 & 5,5 \\
$\mathrm{Ni}$ & 3050,8 & 0,0008 & 10,5 \\
$\mathrm{~V}$ & 2952,1 & 0,01 & 10,5 \\
$\mathrm{~V}$ & 3184,0 & 0,0005 & 10,5 \\
$\mathrm{Mo}$ & 3170,3 & 0,0001 & 10,0 \\
$\mathrm{Zr}$ & 3273,0 & 0,0025 & 4,5 \\
$\mathrm{Cu}$ & 3274,0 & 0,0005 & 7,0 \\
$\mathrm{Co}$ & 3453,5 & 0,0005 & 6,5 \\
$\mathrm{Cr}$ & 4254,3 & 0,0005 & 8,0 \\
$\mathrm{Ba}$ & 4934,1 & 0,003 &
\end{tabular}


Эталонные растворы наносятся на сухие штабики 0,1-миллилитровой микропипеткой с таким расчетом, что бумажная масса штабика на протяжении 7 cм (см. раздел «Приготовление штабиков») может впитать в себя не больше $0,10-0,15$ мл раствора. Исходные эталонные растворы с концентрацией 5 мг/мл (в пересчете на металл) приготовляются отдельно для каждого элемента; из них составляются групповые рабочие растворы с необходимой концентрацией. Капельные эгалоны подвергаются обработке парами кислот аналогично пробам.

Разработанная методика прямого спектрального анализа диктионемового сланца методом бумажного штабика позволяет определять в исходных пробах $\mathrm{Be}, \mathrm{Mn}, \mathrm{Pb}, \mathrm{Ga}, \mathrm{Ni}, \mathrm{V}, \mathrm{Mo}, \mathrm{Cu}, \mathrm{Co}, \mathrm{Cr}, \mathrm{Ba}, \mathrm{Zr}$. Данные о чувствительности и воспроизводимости анализа, без применения внутреннего стандарта, приводятся в табл. 2.

\section{Л ИТЕРАТ У Р А}

Ба бко А. К., М арченко П. В. 1957. Использование соосаждения для получения аналитических концентратов при анализе сплавов. Заводск. лабор., № i1.

Иоханнес Э. Я. 1966. Химико-спектральный метод определения микроэлементов в эстонских кукерситах. Автореф. дисс. канд. наук. Таллин.

Микулин В. П. 1960. Фоторецептурный справочник для фотолюбителей. $M$.

Прокофьев В. К. 1951. Фотографические методы количественного спектрального анализа металлов и сплавов, т. 2. М.-Л.

Р усанов А. К., Алексеев а В. М., Хитров В. Г. 1960. Количественнное спектральное определение редких и рассеянных элементов. М.

Р усанов А. К., В оробьев В. С. 1964. Равномерное вдувание порошков в высокодисперсном состоянии в пламя дуги при спектральном анализе веществ. Заводск. лабор., № 1.

Финкин К. З., Д убос арская Ю. М. 1966. Применение поршневого электрода при спектральном анализе порошковых материалов, Заводск. лабор., № 4 .

Gerbatsch R., Bächer I. 1967. Zur photographischen Registrierung in der Emissionsspektralanalyse. Z. analyt. Chem., B. 225, Nr. 2.

Vi oque A., Albi M. A. 1966. Spektrographische Analyse von Lösungen. Anwendung der $\lambda$-Transformation nach Candler, Mikrochim. Acta (Wien), Nr. 3.

Zimmer K., Török T., Asztalos I., 1966. Vergleichende Untersuchungen über die Genauigkeit und Anwendbarkeit der 1-Transformation, Chem. analit. (Polska), Nr. 6.

Институт геологии

Академии наук Эстонской ССР
Поступила в редакщию $2 /$ II 1968

\section{E. JOHANNES}

\section{MIKROELEMENTIDE SPEKTRAALNE MAARAMINE DIKTUONEEMAKILDAS SIGARIMEETODIL}

Autori poolt väljatöötatud sigarimeetod pōhineb pulbrilise proovi pōletamisel vahelduvvoolukaares filterpaberist sigaris (pikkus $11 \mathrm{~cm}$, läbimōōt $0,2 \mathrm{~cm}$ ). Meetodit iseloomustab elementide fraktsioneeriva aurustumise puudumine ja kaare põlemisrežiimi suur stabiilsus kogu ekspositsiooniaja vältel. Sigarimeetod vōimaldab analüüsida orgaanilist ainet sisaldavaid proove eelnevalt tuhastamata.

Artiklis kirjeldatakse sigarite valmistamist, proovide fluoreerimist HF aurudega, spektrograafi pôletuskambri ehitust, tilketaloonide valmistamist ja gradueerimiskōveraté koostamist.

Sigarimeetodil on diktüoneemakildas võimalik määrata $\mathrm{Be}-, \mathrm{Mn}-, \mathrm{Pb}-, \mathrm{Ga}-, \mathrm{Ni}-$, $\mathrm{V}-, \mathrm{Mo}-, \mathrm{Cu}-, \mathrm{Cr}-, \mathrm{Co}-, \mathrm{Zr}-$ ja Ba-sisaldust otse algproovist keskmise ruutveaga $\pm 5-10 \%$. Analüüsi tundlikkus on $10^{-4}-10^{-3} \%$. 


\section{E. JOHANNES}

\section{SPEKTRALANALYTISCHE BESTIMMUNG VON MIKROELEMENTEN IM DIKTYONEMASCHIEFER MIT HILFE DER PAPIERSTÄBCHEN-METHODE}

Die vom Verfasser ausgearbeitete Papierstäbchen-Methode beruht auf der Verbrennung des untersuchten Pulvers im Wechselstromlichtbogen, in einem Stäbchen aus Filtrierpapier (Länge des Stäbchens $11 \mathrm{~cm}$, Durchmesser 0,2 cm). Das Charakteristische an der Methode ist das Fehlen des fraktionierenden Verdampfens der Elemente und eine hohe Stabilität des Lichtbogens während der ganzen Expositionszeit. Die Papierstäbchen-Methode ermöglicht es, organische Stoffe enthaltende Proben $\mathrm{zu}$ analysieren, ohne sie vorher zu veraschen.

Im Artikel wird die Bereitung der Papierstäbchen beschrieben, die Fluorierung durch HF-Dampf, die Konstruktion der Lichtbogenkammer des Spektrographs, die Herstellung der Tropfenetalons und die Zusammenstellung der Eichkurven.

Durch die Papierstäbchenmethode ist es möglich, im Diktyonemaschiefer den Gehalt an $\mathrm{Be}, \mathrm{Mn}, \mathrm{Pb}, \mathrm{Ga}, \mathrm{Ni}, \mathrm{V}, \mathrm{Mo}, \mathrm{Cu}, \mathrm{Cr}, \mathrm{Co}, \mathrm{Zr}$ und $\mathrm{Ba}$ direkt in der Originalprobe zu bestimmen, wobei der relative Standardabweichung $\pm 5-10 \%$ beträgt. Die Empfindlichkeit der Analyse ist 10-4-10-3\%. 